\title{
THE ROLE OF THE FAMILY EDUCATOR IN EARLY INTERVENTION PROCESS OF CHILDREN WITH DISABILITIES
}

\begin{abstract}
Globally, in the last few decades, the professional treatment of a child with a disability has taken on a different philosophical perspective, that is, from an individual to a complex holistic approach to the whole family. In the modern approach of familyoriented early intervention, particular important is the mutual cooperation between the experts, that is the transdisciplinary model, where the team of expert's transdisciplinary measures provides services aimed to the family and child. Those services are coordinated and integrated to better respond to the complex needs of the child with a disability and his/her family.

For decades, Republic of Macedonia has been facing problems in early detection process and early treatment of people with disabilities. In this direction, we conducted research of 47 families who have a child with a disability. The aim of the research was to detect when they noticed the first problems, who noticed them and when they started with the treatment. According to the results in $80 \%$ of the sample, the first signs of atypical development were noticed by parents (more often by mothers), and in 57\% of the children the treatment started one or more years after receiving the diagnosis.

We believe that the problems with early intervention can be overcome by following the trend of family-oriented early intervention, greater support for families and involvement of the family educator as part of the professional team.
\end{abstract}

Keywords: FAMILY EDUCATOR, FAMILY-ORIENTED EARLY INTERVENTION, FAMILY, CHILDREN WITH DISABILITIES

\section{Why is family education important?}

Family education enables the strengthening of family members through the development of skills, abilities, knowledge for each of the life cycles that the family goes through. It enables the strengthening of family cohesion, as well as interpersonal relations through an educational and preventive approach.

Every parent comes to a point when he/she realizes that he/she do not know all the answers for the growth and development of their child and that they needs a support that will enable parents to maximally stimulate the child's development, to build a proper emotional relationship based on trust and love, to recognize the possible "red flags" in its development that requires 
support, advice or perhaps treatment from professionals. It is especially important that the education offered to the parent is timely, appropriate and systematically organized. In that way, we will provide appropriate education and preparation of parents for possible challenges in parenting process.

At this moment, in the Republic of Macedonia there is no system for education of parents and parenting preparation. Due to the lack of systematic education, parents often seek answers to their dilemmas from other parents who have gone through that developmental period of their child or on internet sites where they facing a lot of incorrect information. This disorganized approach will not take into consideration the individuality in the development of each child and significantly increases the risk of inadequate parent education and risk of making a lot of mistakes in the process of education, growth and stimulate child development.

Especially sensitive problem occurs in parents who have a child with atypical development. Due to the lack of proper information about the child's expected development, often atypical developmental problems are ignored by the parents, hoping that they will disappear on their own. Sometimes, as a child grows, some of the problems that are atypical for a certain developmental period will be overcome as a result of the maturation process and the child will have a harmonious development. But in some developmental problems growth and maturation of the child will not lead to improvement of the situation, contrarily the situation will get worse and the child loses the opportunity for early intervention and early treatment. Family education will allow the parent to make informed choices, that is he/she will know where and when to ask for help.

\section{What is early intervention?}

Early intervention is aimed at preventing difficulties and limiting them to the smallest possible extent, in order to improve the health and well-being of the child, their competence, minimizing developmental difficulties, prevention of functional regressions, promoting adapted parenting and improving family functionality (Pinjatela i Joković-Oreb, 2010).

The early system of support protects the family and society from undesirable events (disintegration of the family, psychosomatic and neurotic disorders, reduction of their working abilities, institutionalization of the child, etc.) (Mamić, 2016). In terms of financial viability, research shows that every dollar invested in an early intervention saves between 7 and 21 dollars, that are going to be spend in the services we need to offer to the person who was not involved in early intervention process (Heckman \& Masterov,2007; Rolnick \& Grunewald, 2003). 


\section{Family-oriented early intervention}

The need for approach changing is recognized and applied in many countries, among which the United States has a leading role. It experienced its beginnings in the early 1970s. This approach provides a system that should answer two important questions in the rehabilitation process, the questions WHO and HOW. The question WHO refers to respecting parents' choices, involve multiple family members, build on family strengths, establish partnerships, and collaborate with families in individualized and flexible ways. Equally important is the question HOW and refer to the specific types of family supports and services that are provided, such as respite care, provision of information (e.g community resources, government benefits, legal rights, information about the nature of disability), and provision of emotional support (e.g. counselling, parent-to-parent match, participation in support groups) (Turnbull et al. 2007).

The National Early Childhood Technical Assistance Centre (NECTAC) reported trends in the percentage of types of services listed on individualized family service plans. Of the 17 services identified in this report, three could generally be described as services to families: (a) family training, counselling, and home visits (b) social work services and (c) respite care (Danaher \& Armijo, 2005).

In the United States, where this approach is best developed, research has shown great satisfaction in families using early intervention services. Bailey et al (2004) collected data in telephone interviews with 2,600 primary caregivers at the approximate time of the child's third birthday. In general, almost three-fourths of families indicated that the amount of services to their child was about right, $91 \%$ rated the overall quality of services as excellent, and $75 \%$ reported early intervention had a lot of impact on their child's overall development. McBride and Peterson (1997) reported that during home visits, $80 \%$ of the interventionist-parent discussions focused on the child's skill development, and $49 \%$ of the early interventionist's time was devoted to working directly with the child.

In Europe, at the request of the German Board of Education, a comprehensive early intervention system was established in 1973 to support regional, family, interdisciplinary early intervention centres. In 2002, 123 regional centres established network of early intervention for all families. The treatment is performed $50 \%$ outpatiently and $50 \%$ at home. The average age at which treatment is offered is 3 to 4 years. It is conducted according to individual needs of each child and consists of one to two sessions per week in a period of two years. On average, 11 therapists from different fields work in teams and complement each other. Such cooperation between experts requires exchange of views and ideas on each individual case, an agreement on the basic conceptual issues, values, aims, specialized fields and organizational issues. 
In Norway, the early intervention system consists of nurses who visit families and children for the first two years, offering them parental advice. This support may last longer if they identify problems in the child's development (Pašilic, 2019).

The new approach to early intervention focuses on understanding the child and family in a holistic and contextual way, focusing on providing opportunities for the child to learn, rather than treating his/her weaknesses in the first place (Dalmau-Montala et al., 2017).

The basic principles of the modern model of early intervention are:

1. Early intervention services are individualized, that is early intervention is focused on the child's strengths, interests and motivation and takes place in the context of his/her daily activities.

2. Early intervention is family-oriented, meaning it is based on the unique strengths of each family and their priorities.

3. Early intervention is carried out in a team, the expert team and the family work together to solve problems and make decisions.

4. The services within the early intervention are on scientifically based practice that is confirmed by evidence.

5. Early intervention is focused on results.

6. Early intervention is in balance with the context in which the child functions. (Workgroup on Principles and Practices in Natural Environments, 2008).

We need to provide quality education for parents so they can provide adequate support to their child. One of the main goals of early intervention is to help the parent understand the nature of the child's problems and how they will affect the child's further development. In this way, we increase the capacity of parents, help them adjust their expectations and influence children's developmental abilities (Pašilic, 2019).

The literature highlights three types of interactions that affect a child's development: the parent-child transaction, the family organization of the child's experience, and the child's health and safety. In early intervention, especially in the first year of the child, it is recommended that the therapist work at home. All parents who participated in the Home Visitor Program expressed satisfaction with the therapist's visit and their child's progress (Guralnick, 2011).

\section{The role of parents in early intervention in the Republic of North Macedonia}

When it comes to parenting, there are no rights or wrongs, only informed choices. That's why it's critical that the information you base your parenting decisions on be accurate, up-to-date, and trusted. Awareness of key issues related to the child's developmental disabilities and their potential impact on the family system and is essential for the process of family-oriented early intervention (Malone et al, 1997). 
System of rehabilitation and education of children with disabilities in the Republic of Macedonia for decades has been facing a lot of problems in the process of early detection and early treatment of people with disabilities. In general, early detection in our health care system succeeds only in those situations where problems are "obvious", when they are expressing phenotypic or genotypic characteristics. Chromosomopathies, cerebral palsy, total sensory impairment (total blindness, deafness), etc. are the most common. Many of the problems that significantly change the functioning of the personality remain undiagnosed for a long period of time, thus we are losing the opportunity for early intervention and developing of the full potential of children with disabilities.

Low vision and deafness as partial damage of the sensory organs often cannot be detected by parents. Specific behaviours that manifest these children because of the impairment, parents usually attribute them to the current mood of the child, their interests, their will and similar. In the Republic of Macedonia, in a period of 5 years (from 2014 to 2018) within the project for visual impairment people, with a special optometric device was performed ophthalmic screening of 30214 children of preschool and early school age, and 6587 (21, $8 \%$ ) of them are referred for additional examination. In the group of children referred to a further examination we detected children with serious vision problems as glaucoma, cataracts, exceptionally high dioptres, conditions which, if treated in time provide significant vision retention (USAID and LCIF Children with visual impairment project, 2018).

A few months ago we conducted a research of 45 families who have a child with intellectual disability - students in special primary school (POU. Dr. Zlatan Sremac and POU.Idnina), which confirmed all the problems we face in the early detection and early diagnosis. According to the results, 17 children $(38 \%)$ were diagnosed at birth or up to one year of age, and these are children who have been diagnosed with Down syndrome (chromosomopathy), cerebral palsy, or combined developmental disabilities. The remaining 28 children $(62 \%)$ have received their diagnosis after the second year, these children are diagnosed with autism at an average age of diagnosis of 2.5 years and mild intellectual disability with an average age of diagnosis of 3.6 years. It is important to note that in children who was not diagnosis during the first few months after birth, in 36 children or $80 \%$, the first signs of atypical development were being noticed by their parents (more often the mother).

An important indicator in our research was the time elapsed from the moment of recognizing the first signs that indicate atypical development, to the moment when treatment was started. We analysed this parameter on 37 parents, those who answered on this question. The following graph show the obtained results. 
Graph 1:

How long did it take from the diagnosis to the treatment of the child?

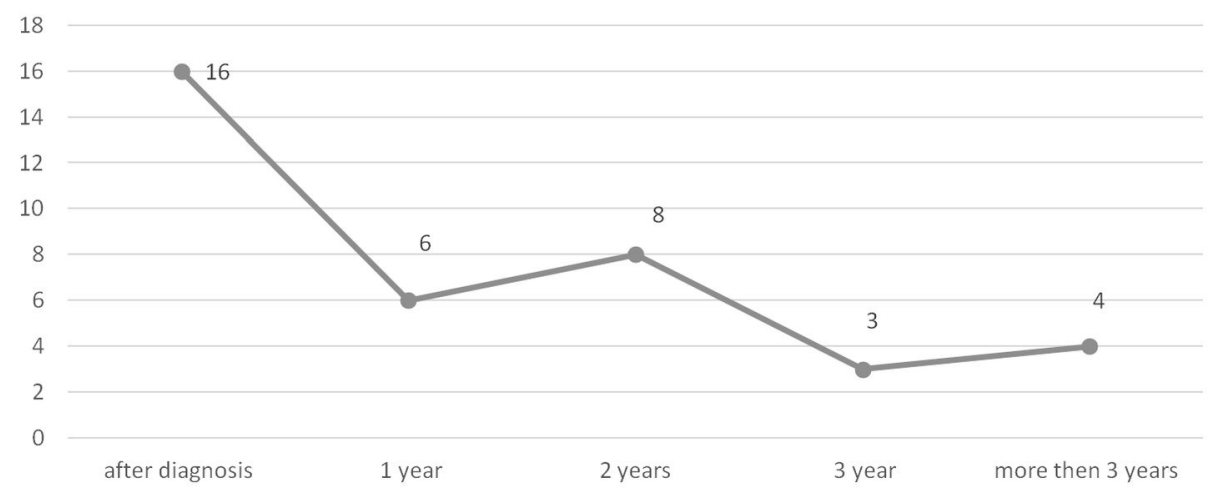

According to the obtained data, 16 parents or $43 \%$ started treatment immediately after noticing the first signs of developmental problems, but the remaining 21 parents or $57 \%$ started with a treatment one, two, three and more years after first signs. This is a serious statistical indicator of the need of support to these families. According to the results of this group of parents, 21 parents ignored the referrals of the doctor or the expert team that made the diagnosis, ignored the "red development flags", for whom they may have hoped to pass on their own, and feared to accept reality or a number of other possible reasons. As a result of that 21 children had additional development problems, they lost the opportunity for early intervention and the possibility for maximum individual development.

\section{Legislation to support families}

In 2019, a new Law on Social Protection was adopted in the Republic of Macedonia, in which families and services provided for families receive a significant importance. In this regard, we would mention the services offered within the social prevention and social services.

Article 73 is about the counselling services, which are defined in order to prevent, alleviate and overcome the consequences of the individual and family social problems. Parental counselling is also defined as part of these services.

At the same time, the law provides home services as integrated social services and there are provided for people with temporarily or permanently reduced functional capacity, but they are not intended for family care or family support. 
Based on the Low on Social protection, we would conclude that we have a partially established legal framework for organizing counselling centres for preparing families for parenting, however we have a lot of open questions about how to organize them, the organization of the transdisciplinary approach to work, defining home services and at the end connecting these families counselling centres with health facilities that offer health care to children at risk.

\section{Recommendations}

Some of the problems with early intervention can be overcome by including the family educator in the early intervention team. Through family counselling, whether there are in preschools institutions, health care facilities, or as independent units, they can greatly increase the educational potential of a wider range of parents who will know when and where to ask for help.

The role of the family educator in improving early intervention will include:

Preventive measures:

- Improving the educational potential and skills of future parents. In this way, future parents will have information about the developmental periods that their child is going through, will be informed what to expect and which indicators would be alarming to seek higher level help;

- Family educator would be available to address any dilemmas regarding child development and parenting. All problems that the family educator considers to be more complex and not within his/her competence will be solved in consultation with appropriate professional profiles from appropriate institutions;

- Monitoring the child's development at home, conducted through frequent home visits. Such visits will provide the family educator with a better insight into family dynamics, parenting roles, monitoring the child's development and behavior at home.

Regarding the work with children with disabilities and with their families, the family educator will provide:

- Assessment of the capacity of the family to meet the needs of children with disabilities;

- Building relationship based on a trust with family members and involving all members in the process of rehabilitation and education of the child with disabilities;

- Educating parents about their child's problems, expectations and challenges;

- Preserving the mental health of family members;

- Individual work with parents of children with disabilities, in order to organize a stimulating home environment; 
- Organizing group meetings to support family members (parents and siblings);

- Organizing a parent-to-parent activity, an established practice when an experienced parent who has already gone through certain challenges works with a parent who is going through the same or similar challenges;

- Informing parents about their legal rights and obligations and assistance in achieving them;

In coordination with other profiles of the professional team (special educator and rehabilitator, psychologist, social worker, etc.) will prepare an individual family work plan, which will be the basis in working with family members.

\section{References:}

Bailey, D., SCARborough, A., HebBeler, K., SpiKer, D., \& MAlliK, S. (2004). National early intervention longitudinal study: Family outcomes at the end of early intervention. Menlo Park, CA: SRI International.

CARPENTER, B. (2001). Families in context: Emerging trends in early intervention and family support. London: David Fulton Publishers.

DalmaU-MONTALA, M ET AL., (2017). How to implement the family-centered model in early intervention. Anales de Psicologíal Annals of Psychology, 33 (3), 641-651.

DANAHER, J. \& ARMiJO, C. (Eds.). (2005). Part C updates (7th ed.). Chapel Hill: University of North Carolina, FPG Child Development Institute, National Early Childhood Technical Assistance Center.

GURALNICK, M. J. (1991). The next decade of research on the effectiveness of early intervention. Exceptional children, 58(2), 174-183.

HECKMAN, J. J., \& MASTEROV, D. V. (2007). The productivity argument for investing in young children. Applied Economic Perspectives and Policy, 29(3), 446-493.

MALONE, DM., MANDERS, J., STEWART S. (1997)_A rationale for family therapy specialization in early intervention. Available at: https://www.ncbi.nlm.nih.gov/pubmed/9058553 [Accessed 15.4.2020]

MAMIĆ, P. (2016). Usluge rane intervencije: perspektiva obitelji djece s odstupanjima u psihomotoričkom razvoju (Doctoral dissertation, University of Zagreb. Faculty of Education and Rehabilitation Sciences.).

MCBRIDE, S. L., \& PETERSON, C. (1997). Homebased early intervention with families of children with disabilities: Who is doing what? Topics in Early Childhood Special Education, 17, 209-233.

PAŠILIC, A (2019) Rana intervencija usmjerena na porodici. Available at: 
file://C:/Users/DELL1/Downloads/Ranaintervencijausmjerenanaporodic updf.pdf [Accessed 2.5.2020]

PinjATElA, R., \& JOKOviĆ OREB, I. (2010). Rana intervencija kod djece visokorizične za odstupanja u motoričkom razvoju. Hrvatska revija za rehabilitacijska istraživanja, 46(1), 80-102.

ROLNICK, A., \& GRUNEWALD, R. (2003). Early childhood development: Economic development with a high public return. The Region, 17(4), 6-12.

TURNBULL ET AL. (2007) Family support and services in early intervention, Journal of early intervention, 29 (3), 187-206

USAID and LCIF Children with visual impairment project. (2018), Issue 4. Available at: http://cvip.seeu.edu.mk/web/lcif-newsletter/ [Accessed 12.4.2020]

WORKGROUP ON PRINCIPLES AND PRACTICES IN NATURAL ENVIRONMENTS, OSEP TA Community of Practice: Part C Settings. (2008, February). Agreed upon practices for providing early intervention services in natural environments. Available at: http://www.ectacenter.org/ pdfs/topics/families/AgreedUponPractices_FinalDraft2_01_08.pdf [Accessed 2.5.2020]

ЗАКОН ЗА СОЦИЈАЛНА ЗАШТИТА. (2019), Службен весник на РСМ, бр. 104. Available at: mtsp.gov.mk/content/pdf/zakoni/2019/28.5_zakon_SZ.pdf [Accessed 3.5.2020] 